\title{
Identification a nonsense mutation of $A P C$ gene in Chinese patients with familial adenomatous polyposis
}

\author{
HAISHAN LI ${ }^{1}$, LINGLING ZHANG $^{2}$, QUAN JIANG $^{3}$, ZHENWANG SHI $^{4}$ and HANXING TONG ${ }^{3}$ \\ ${ }^{1}$ Department of Emergency, The Second People's Hospital of Hefei, Hefei, Anhui 230601; ${ }^{2}$ Department of Oncology, \\ Binzhou People's Hospital, Binzhou, Shandong 256600; ${ }^{3}$ Department of General Surgery, Zhongshan Hospital, \\ Fu Dan University, Shanghai 200032; ${ }^{4}$ Department of Gastroenterology, The Second \\ People's Hospital of Hefei, Hefei, Anhui 230601, P.R. China
}

Received July 26, 2015; Accepted December 19, 2016

DOI: $10.3892 /$ etm. 2017.4122

\begin{abstract}
Familial adenomatous polyposis (FAP; Mendelian of Inherintance in Man ID, 175100) is a rare autosomal dominant disorder characterized by the development of numerous adenomatous polyps throughout the colon and rectum associated with an increased risk of colorectal cancer. FAP is at time accompanied with certain extraintestinal manifestations such as congenital hypertrophy of the retinal pigment epithelium, dental disorders and desmoid tumors. It is caused by mutations in the adenomatous polyposis coli $(A P C)$ gene. The present study reported on a Chinese family with FAP. Polymerase chain reaction and direct sequencing of the full coding sequence of the $A P C$ gene were performed to identify the mutation in this family. A nonsense mutation of the $A P C$ gene was identified in this pedigree. It is a heterozygous $\mathrm{G}>\mathrm{T}$ substitution at position 2,971 in exon 15 of the APC gene, which formed a premature stop codon at amino acid residue 991 (p.Glu991*). The resulting truncated protein lacked 1,853 amino acids. The present study expanded the database on $A P C$ gene mutations in FAP and enriched the spectrum of known germline mutations of the $A P C$ gene. Prophylactic proctocolectomy may be considered as a possible treatment for carriers of the mutation.
\end{abstract}

\section{Introduction}

Familial adenomatous polyposis (FAP; MIM 175100) is a rare autosomal dominant disorder, which is characterized by the development of numerous adenomatous polyps throughout the colon and rectum (1). It is a pre-cancerous disease, which

Correspondence to: Dr Hanxing Tong, Department of General Surgery, Zhongshan Hospital, Fu Dan University, 180 Fenglin Road, Shanghai 200032, P.R. China

E-mail: thx121@163.com

Key words: familial adenomatous polyposis, mutation analysis, $A P C$ gene develops into colorectal cancer (CRC) in almost all patients without early diagnosis and colorectal surgery (2). FAP may have extracolonic manifestations, including osteomas, dental abnormalities, congenital hypertrophy of the retinal pigment epithelium (CHRPE) and upper gastrointestinal polyps (3). The incidence of FAP at birth is estimated to be 3-10 per 100,000 individuals (4).

FAP has three phenotypes: Classic FAP (CFAP), attenuated FAP (AFAP) and MUTYH-associated polyposis (MAP) (5), with CFAP and AFAP being autosomal dominant disorders. It has been identified that the adenomatous polyposis coli (APC) gene on chromosome $5 \mathrm{q} 22.2$ is associated with CFAP and AFAP (6). MAP is a recessive dominant disorder caused by mutations in the MUTYH gene (7). In the present study, mutations of the $A P C$ gene were detected in a Chinese family with CFAP by sequencing analysis, and a nonsense mutation was identified.

\section{Materials and methods}

Patients. A 40 year-old Chinese male patient was seen at the Department of Emergency of the Second People's Hospital of Heifei (Hefei, China) in August 2011, due to experiencing hematochezia for 1 day. In the past year, he had frequently suffered from moderate diarrhea with scurrying pain around the umbilicus. His medical history was not indicative of colitis and hemorrhoids. The patient was a non-smoker and drank alcohol socially. Colonoscopy findings revealed a huge neoplasm with surface erosion and bleeding $35-38 \mathrm{~cm}$ away from the anus (Fig. 1A), as well as congestion, edema and diffused polyps with diameters of $0.3-0.8 \mathrm{~cm}$ from the ascending colon to the rectum mucosa (Fig. 1B). The primary diagnosis was FAP. Subsequently, the patient successfully underwent laparoscopic total colectomy and ileal anal anastomosis. Postoperative recovery was good. Pathological findings revealed an abundance of multiple tubular papillary adenoma with low-level intraepithelial neoplasia throughout the entire colon. The family comprised 18 members that spanned three generations, including 3 male (one of which was the proband of the present study) and 2 female individuals affected by FAP (Fig. 2). A similar disease course and abnormalities were found in these patients. 

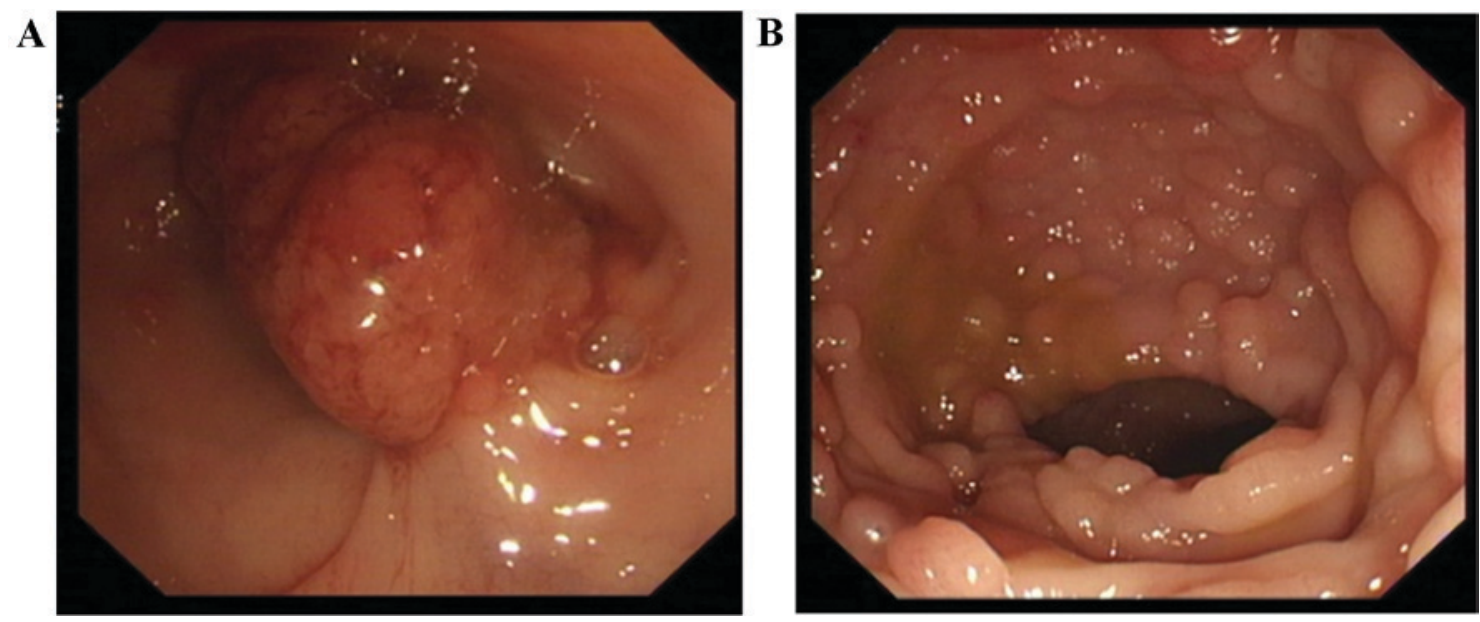

Figure 1. Clinical manifestations of the proband. Endoscopy revealed (A) a large mass in the rectum and (B) innumerable polyps in the rectum and sigmoid colon.

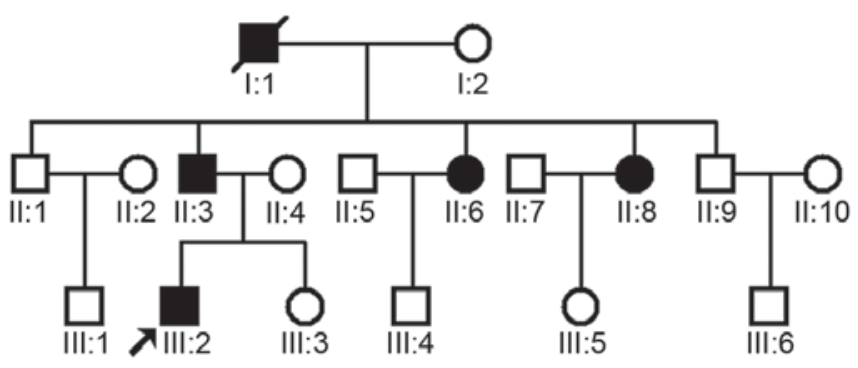

Figure 2. Pedigree of the present study affected by familial adenomatous polyposis. The arrow indicates the proband.

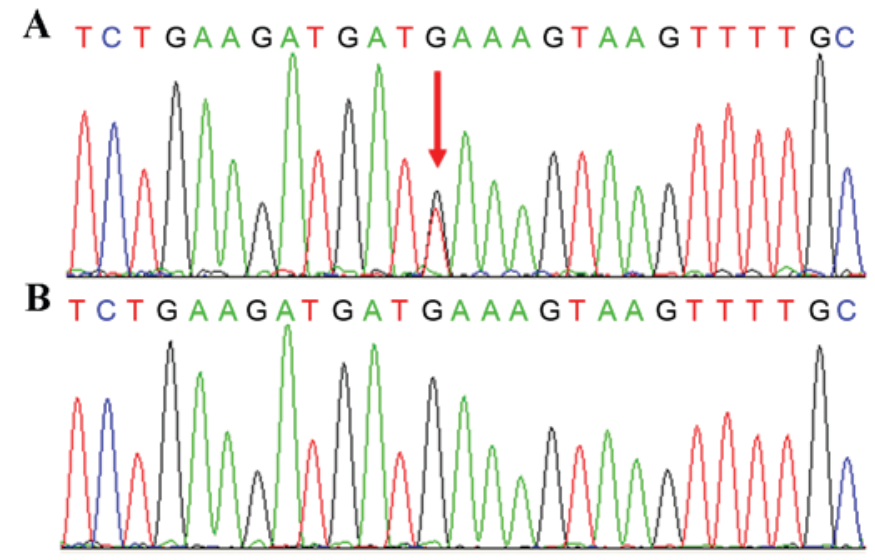

Figure 3. APC gene mutation in the proband. (A) Heterozygous nonsense mutation c.2991G >T in exon 15. (B) Sequence of exon 15 of the $A P C$ gene in a normal subject. The red arrow indicates the mutation. $A P C$, adenomatous polyposis coli.

Mutational analysis. The protocol of the present study was approved by the Ethics Committee of the Second People's Hospital of Heifei (Hefei, China) and Zhongshan Hospital (Shanghai, China) and all patients provided written informed consent to be included in the present study. Peripheral blood samples were obtained from the four living patients (II:3, II:6, II:8 and the proband III:2; Fig. 2). In addition, samples from 100 unrelated population-matched controls from Zhongshan
Hospital were sequenced for mutations to exclude the possibility that it is a polymorphism in the $A P C$ gene. DNA was extracted according to standard methods. Primers flanking all 15 coding exons and intron-exon boundaries of the $A P C$ gene were extracted using the web-based version of the Primer 3.0 program (http://primer3.ut.ee/). The primers used are listed in Table I. The $A P C$ gene of this family was analyzed by direct sequencing in reaction conditions as previously described (8). Subsequent to amplification, a QIAquick PCR Purification kit (Qiagen, Hilden, Germany) was used to purify the products. The APC gene was sequenced using an ABI PRISM ${ }^{\circledR} 3730$ automated sequencer (Applied Biosystems; Thermo Fisher Scientific, Inc., Waltham, MA, USA). Sequence comparisons and analysis were performed using Phred-Phrap-Consed version 12.0 software (http://www.phrap.org/phredphrapconsed.html). Mutations were identified by comparison with the reported complementary DNA reference sequence (GenBank accession no, NM_000038).

\section{Results}

Sequencing results of the proband revealed a nonsense mutation (c.2971G>T, p.Glu991*) located at exon 16 of the APC gene (Fig. 3A). This mutation was also verified in the other three patients, but excluded in the unaffected family members and 100 unrelated population-match controls (Fig. 3B). This mutation forms a premature stop codon at amino acid residue 991, which results in a truncated protein short of 1,853 amino acids. This mutation has already been reported a patient with hereditary cancer-predisposing syndrome (https://www.ncbi. nlm.nih.gov/clinvar/15587313/). The present study confirmed this mutation in a Chinese family with CFAP. The result demonstrates that this mutation may be a hotspot mutation in diverse population.

\section{Discussion}

FAP is an autosomal dominant disease characterized by the development of hundreds to thousands of adenomas in the colon and rectum, and is at times accompanied with certain extra-intestinal manifestations such as CHRPE, dental 
Table I. The primers sequences of APC gene.

\begin{tabular}{|c|c|c|}
\hline Name & Sequence $\left(5^{\prime}-3^{\prime}\right)$ & Product length $(\mathrm{bp})$ \\
\hline APC-E02_F & СTCTTAGATGCTGCTACTTGA & 800 \\
\hline APC-E02_R & GGATAGAACCAGGTACTGAC & \\
\hline APC-E03_F & ACAGAGACTCCCCATAATCA & 587 \\
\hline APC-E03_R & GACTGGCAGAATAGCAACAA & \\
\hline APC-E04_F & GTTGCTTGAAAATTCCAGTG & 642 \\
\hline APC-E04_R & GCTCTAAGTGTTAGCTATCAC & \\
\hline APC-E05_F & AGCCTTTGGTGAAGTGTAAG & 640 \\
\hline APC-E05_R & TTGAACCCTGAGGTCCTCTA & \\
\hline APC-E06_F & TAACCTCACTCTAACTGGAC & 676 \\
\hline APC-E06_R & GAAGACCACCATCTAACTCT & \\
\hline APC-E07_F & TGATTTGACATAACCCTGAGC & 604 \\
\hline APC-E07_R & ACCTTCCCTGGTCTTAATGC & \\
\hline APC-E08_F & GGATGGCATTCCTGTGAGTC & 703 \\
\hline APC-E08_R & GCAAACCTATTCAAGGCAAGC & \\
\hline APC-E09_F & CTGCAGTTTAATGCTCATATGC & 377 \\
\hline APC-E09_R & GCAAAGTAGTCATGGCATTAGT & \\
\hline APC-E10_F & CAGTTTGTTAGTGAGTATGC & 860 \\
\hline APC-E10_R & GCACATAACATTTTCCTTTG & \\
\hline APC-E11_F & ACTTAGTCAAGGGCAGATGA & 468 \\
\hline APC-E11_R & GCTGATAACAGAAGTTGGTG & \\
\hline APC-E12_F & GGAGAAACTGGCATAAAATGG & 578 \\
\hline APC-E12_R & TCACTACTGTGTTCCATCTG & \\
\hline APC-E13_F & ACTTGTAGGGATCATTTCTGTG & 599 \\
\hline APC-E13_R & ATTGCACAACTGCССТCTAA & \\
\hline APC-E14_F & CAGTAACCTCAAGCTCCTGG & 828 \\
\hline APC-E14_R & CGAGACCAGCCTTACCAACA & \\
\hline APC-E15_F & AAGTTCTTAATTTACCAGTG & 486 \\
\hline APC-E15_R & GTAGTTATCTTTTCACAGTA & \\
\hline APC-E16-1_F & ATTGGGTCAGAATAGGAAATG & 890 \\
\hline APC-E16-1_R & TCTGTTGCTGGATGGTAGTT & \\
\hline APC-E16-2_F & GTCCCAAGGCATCTCATCGT & 667 \\
\hline APC-E16-2_R & GCTGGGTATTGACCATAACTGC & \\
\hline APC-E16-3_F & ATAGTGTCAGTAGTAGTGATGG & 498 \\
\hline APC-E16-3_R & GACACAAAGACTGGCTTACA & \\
\hline APC-E16-4_F & ATCGAGTGGGTTCTAATCATGG & 635 \\
\hline APC-E16-4_R & TGGAACTTCGCTCACAGGAT & \\
\hline APC-E16-5_F & ATCCAAGTTCTGCACAGAGT & 739 \\
\hline APC-E16-5_R & CTCTGAACTGCAGCATTTAC & \\
\hline APC-E16-6_F & GCTCAAACCAAGCGAGAAGT & 750 \\
\hline APC-E16-6_R & TCTGCCTTCTGTAGGAATGG & \\
\hline APC-E16-7_F & TGCTGGAGAAGGAGTTAGAG & 701 \\
\hline APC-E16-7_R & GGTTGGAGGTTAGTTCTGTG & \\
\hline APC-E16-8_F & GATGATGTTGACCTTTCCAG & 574 \\
\hline APC-E16-8_R & CATTATCACCCTTGAGTCTTG & \\
\hline APC-E16-9_F & ATCAGGCTATGCTCCTAAATCA & 824 \\
\hline APC-E16-9_R & TTTCACAGATGGCTTGGCTC & \\
\hline APC-E16-10_F & GATTCATATTCCAGGAGTTCG & 475 \\
\hline APC-E16-10_R & GGCATTCTTGGATAAACCTG & \\
\hline APC-E16-11_F & TGAGCCAACAGAACCTTACC & 777 \\
\hline APC-E16-11_R & AGGAAACGGTCTGAGAAGTAC & \\
\hline APC-E16-12_F & CTCTATTTCAGGAACCAAAC & 878 \\
\hline APC-E16-12_R & ССТСТААСАAGAАТСАААСС & \\
\hline
\end{tabular}

APC, adenomatous polyposis coli; F, forward; R, reverse. 
disorders and desmoid tumors (9). $A P C$ is a tumor suppressor gene located on the long arm of chromosome 5 in band q21, whose mutation is responsible for CFAP and AFAP. The length of the gene is $108,353 \mathrm{bp}$ and it is divided into 15 exons (10). The APC protein has multiple domains that mediate oligomerization as well as binding to a variety of intracellular proteins and has a central role in Wnt signaling by regulating of degradation of proteins associated with this pathway (11).

To date, according to the information available in public databases, such as The Human Gene Mutation Database (http://www.hgmd.cf.ac.uk/ac/index.php), >1,000 different $A P C$ mutations have been reported, among which $>100$ cases were contributed by Chinese studies (12-17). While the type of $A P C$ gene mutation varies, nonsense and frameshift mutations are most frequently seen, and have been predicted to produce truncated proteins, finally leading to the development of diseases (17).

According to certain studies, most FAP patients inherit one $A P C$ allele mutation from their parents with the other allele being normal. Diseases would not occur until the normal allele undergoes a new mutation (11). It has also been estimated that new germline mutations of $A P C$ account for one third of FAP patients who have no family history of FAP (18). Certain studies have attempted to explore the correlation between specific $A P C$ mutations with the clinical phenotype. Certain correlations do exist, for instance, mutations between codons 169 and 1,578 were generally associated with CFAP (19-21). Mutations downstream of codon 1,596 are frequently seen in AFAP (11). Mutations between codons 1,445 and 1,578 were associated with desmoid tumors, whereas those between codons 279 and 1,309 were correlated with the development of duodenal polyposis (22-24). While it appears promising to predict a patient's phenotype by the mutation site of the APC gene, this was proven to not be feasible in clinical practice. Considerable variability has been found in the presentation of specific phenotypes in patients with identical mutations (25). This indicates that the phenotype is associated with more factors than genetic mutations (25).

In the present study, the nonsense mutation c.2971G $>\mathrm{T}$ (p.E991*) was identified in exon 15 of the APC gene. The resulting truncated protein lacked 1,853 amino acids. The wild-type sequence in the affected region of the $A P C$ gene is highly evolutionarily conserved in different species, including humans, mice, rats, frogs, zebrafish and pufferfish. Through mutation-associated truncation, the APC protein loses its microtubule binding domain, end binding-1 binding domain, $\beta$-catenin degradation domain and $\beta$-catenin binding domain, which is likely to affect the proliferation and differentiation status of cells and eventually results in colorectal polyps and cancer $(26,27)$. In addition, this nonsense mutation may lead to nonsense-mediated decay of $A P C$ transcripts. The mutation results in haplo-insufficiency of $A P C$, which leads to development of diseases.

While evidence strongly links $A P C$ gene mutations with FAP, the single factor is not sufficient to explain the etiology of the disease. It is estimated that 10-30 percent of patients with classical FAP do not have any detectable APC mutation. A proportion of FAP patients have MAP, an autosomal recessive polyposis syndrome caused by biallelic mutations in the
MUTYH gene. Therefore, it is recommended that patients who have a recessive family history of FAP are evaluated for a MUTYH mutation (28).

Surgery remains to be the only option to cure the disease, although it remains debatable which surgical option is the golden standard. However, given the substantial risk of rectal cancer developing after colectomy and ileorectal anastomosis, most experts recommend total proctocolectomy for typical FAP patients with multiple rectal adenomas (29). Diet and drugs have been shown to have a role in preventing cancer. Caloric restriction or diet with olive oil, fruits and vegetables significantly reduced the number of polyps in a mouse model of multiple intestinal neoplasia with genetically manipulated APC (30). Randomized trials have shown that celecoxib causes regression of established adenomatous polyps in individuals with FAP. In 2001, the US Food and Drug Administration approved the use of celecoxib in patients with FAP presenting with polyps (31). The proband of the present study successfully underwent laparoscopic total colectomy and ileal anal anastomosis and postoperative recovery was good.

In conclusion, the present study identified a mutation in the $A P C$ gene in a Chinese family with FAP. The present study added novel variants to the knowledge of $A P C$ mutations in FAP. Identification of novel mutations will be useful to reveal the correlation between genotypes and phenotypes.

\section{Acknowledgements}

This study was supported by a grant from the Shanghai Science and Technology Innovation Action Plan (nano-science and technology projects; no. 12nm0501402). The authors would like to thank all patients and control individuals for their participation in this study.

\section{References}

1. Rhodes $\mathrm{M}$ and Bradburn DM: Overview of screening and management of familial adenomatous polyposis. Gut 33: 125-131, 1992.

2. Martellucci J, Civitelli S, Dhamo A and Tanzini G: Familial colorectal cancer: A concept revisited. Colorectal Dis 11: 133-137, 2009.

3. Li FP, Thurber WA, Seddon J and Holmes GE: Hepatoblastoma in families with polyposis coli. JAMA 257: 2475-2477, 1987.

4. Gibbons DC, Sinha A, Phillips RK and Clark SK: Colorectal cancer: No longer the issue in familial adenomatous polyposis? Fam Cancer 10: 11-20, 2011.

5. Aretz S: The differential diagnosis and surveillance of hereditary gastrointestinal polyposis syndromes. Dtsch Arztebl Int 107: 163-173, 2010.

6. Snow AK, Tuohy TM, Sargent NR, Smith LJ, Burt RW and Neklason DW: APC promoter 1B deletion in seven American families with familial adenomatous polyposis. Clin Genet 88 : 360-365, 2015.

7. Inra JA, Steyerberg EW, Grover S, McFarland A, Syngal S and Kastrinos F: Racial variation in frequency and phenotypes of APC and MUTYH mutations in 6,169 individuals undergoing genetic testing. Genet Med 17: 815-821, 2015.

8. Li M, Yang L, Li C, Jin C, Lai M, Zhang G, Hu Y, Ji J and Yao Z: Mutational spectrum of the ADAR1 gene in dyschromatosis symmetrica hereditaria. Arch Dermatol Res 302: 469-476, 2010.

9. Plawski A, Banasiewicz T, Borun P, Kubaszewski L, Krokowicz P, Skrzypczak-Zielinska M and Lubinski J: Familial adenomatous polyposis of the colon. Hered Cancer Clin Pract 11: $15,2013$. 
10. Liao DX, Li B, Du XM, Yu JH, Chang H, Wu ZQ, Hao HJ, Wang YX, Han WD, Cheng SJ and Luo CH: Two Chinese pedigrees for adenomatous polyposis coli: New mutations at codon 1309 and predisposition to phenotypic variations. Fam Cancer 13: 361-368, 2014

11. Half E, Bercovich D and Rozen P: Familial adenomatous polyposis. Orphanet J Rare Dis 4: 22, 2009.

12. Tang C, Guo J, Chen H, Yao CJ, Zhuang DX, Wang Y, Tang WJ, Ren G, Yao Y, Wu JS, et al: Gene mutation profiling of primary glioblastoma through multiple tumor biopsy guided by 1H-magnetic resonance spectroscopy. Int J Clin Exp Pathol 8: 5327-5335, 2015.

13. Chen QW, Zhang XM, Zhou JN, Zhou X, Ma GJ, Zhu M, Zhang YY, Yu J, Feng JF and Chen SQ: Analysis of small fragment deletions of the APC gene in Chinese patients with familial adenomatous polyposis, a precancerous condition. Asian Pac J Cancer Prev 16: 4915-4920, 2015.

14. Qiu T, Guo H, Zhao H, Wang L and Zhang Z: Next-generation sequencing for molecular diagnosis of lung adenocarcinoma specimens obtained by fine needle aspiration cytology. Sci Rep 5: 11317, 2015.

15. Chen K, Xia G, Zhang C and Sun Y: Correlation between smoking history and molecular pathways in sporadic colorectal cancer: A meta-analysis. Int J Clin Exp Med 8: 3241-3257, 2015.

16. Zhang Y, Lu G, Hu Q, Wang X, Li C, Mao Y and Cui M: A de novo germline mutation of APC for inheritable colon cancer in a Chinese family using multigene next generation sequencing. Biochem Biophys Res Commun 447: 503-507, 2014

17. Song G, Yuan Y, Zheng F and Yang N: Novel insertion mutation p.Asp610GlyfsX23 in APC gene causes familial adenomatous polyposis in Chinese families. Gene 516: 204-208, 2013.

18. De Queiroz Rossanese LB, De Lima Marson FA, Ribeiro JD, Coy CS and Bertuzzo CS: APC germline mutations in families with familial adenomatous polyposis. Oncol Rep 30: 2081-2088, 2013.

19. Järvinen HJ and Peltomäki P: The complex genotype-phenotype relationship in familial adenomatous polyposis. Eur J Gastroenterol Hepatol 16: 5-8, 2004.

20. Giardiello FM, Krush AJ, Petersen GM, Booker SV, Kerr M, Tong LL and Hamilton SR: Phenotypic variability of familial adenomatous polyposis in 11 unrelated families with identical APC gene mutation. Gastroenterology 106: 1542-1547, 1994.

21. Nagase H, Miyoshi Y, Horii A, Aoki T, Ogawa M, Utsunomiya J, Baba S, Sasazuki T and Nakamura Y: Correlation between the location of germ-line mutations in the APC gene and the number of colorectal polyps in familial adenomatous polyposis patients. Cancer Res 52: 4055-4057, 1992.
22. Caspari R, Olschwang S, Friedl W, Mandl M, Boisson C, Böker T, Augustin A, Kadmon M, Möslein G, Thomas G, et al: Familial adenomatous polyposis: Desmoids tumours and lack of ophthalmic lesions (CHRPE) associated with APC mutations beyond codon 1444. Hum Mol Genet 4: 337-340, 1995.

23. Soravia C, Berk T, Madlensky L, Mitri A, Cheng H, Gallinger S, Cohen Z and Bapat B: Genotype-phenotype correlations in attenuated adenomatous polyposis coli. Am J Hum Genet 62: 1290-1301, 1998

24. Touriño R, Conde-Freire R, Cabezas-Agrícola JM, RodríguezAves T, López-Valladares MJ, Otero-Cepeda JL and Capeans C: Value of the congenital hypertrophy of the retinal pigment epithelium in the diagnosis of familial adenomatous polyposis. Int Ophthalmol 25: 101-112, 2004.

25. Zeichner SB, Raj N, Cusnir M, Francavilla M and Hirzel A: A de novo germline APC mutation (3927del5) in a patient with familial adenomatous polyposis: Case report and literature review. Clin Med Insights Oncol 6: 315-323, 2012.

26. Grady WM and Markowitz SD: Hereditary colon cancer genes. Methods Mol Biol 222: 59-83, 2003

27. Näthke I: APC at a glance. J Cell Sci 117: 4873-4875, 2004.

28. Russell AM, Zhang J, Luz J, Hutter P, Chappuis PO, Berthod CR, Maillet P, Mueller $\mathrm{H}$ and Heinimann K: Prevalence of $\mathrm{MYH}$ germline mutations in Swiss APC mutation-negative polyposis patients. Int J Cancer 118: 1937-1940, 2006.

29. Aziz O, Athanasiou T, Fazio VW, Nicholls RJ, Darzi AW, Church J, Phillips RK and Tekkis PP: Meta-analysis of observational studies of ileorectal versus ileal pouch-anal anastomosis for familial adenomatous polyposis. Br J Surg 93: 407-417, 2006.

30. Mai V, Colbert LH, Berrigan D, Perkins SN, Pfeiffer R, Lavigne JA, Lanza E, Haines DC, Schatzkin A and Hursting SD: Calorie restriction and diet composition modulate spontaneous intestinal tumorigenesis in Apc (Min) mice through different mechanisms. Cancer Res 63: 1752-1755, 2003.

31. Steinbach G, Lynch PM, Phillips RK, Wallace $M H$, Hawk E, Gordon GB, Wakabayashi N, Saunders B, Shen Y, Fujimura T, et al: The effect of celecoxib, a cyclooxygenase-2 inhibitor, in familial adenomatous polyposis. N Engl J Med 342: 1946-1952, 2000. 